\title{
Making Pastoralists Count: Geospatial Methods for the Health Surveillance of Nomadic Populations
}

\author{
Hannah Wild, ${ }^{1 \star}$ Luke Glowacki, ${ }^{2 \star}$ Stace Maples, ${ }^{3}$ Iván Mejía-Guevara, ${ }^{4,5}$ Amy Krystosik, ${ }^{6}$ Matthew H. Bonds, ${ }^{7}$ Abiy Hiruy, ${ }^{8}$ \\ A. Desiree LaBeaud, ${ }^{6}$ and Michele Barry ${ }^{9}$ \\ ${ }^{1}$ Stanford University School of Medicine, Stanford, California; ${ }^{2}$ Department of Anthropology, Pennsylvania State University; ${ }^{3}$ Stanford Geospatial \\ Center, Stanford University, Stanford, California; ${ }^{4}$ Department of Biology, Stanford University, Stanford, California; ${ }^{5}$ Stanford Center for Population \\ Health Sciences, Stanford University School of Medicine, Stanford, California; ${ }^{6}$ Division of Infectious Disease, Department of Pediatrics, \\ Stanford University School of Medicine, Stanford, California; ${ }^{7}$ Department of Global Health and Social Medicine, Harvard Medical School, \\ Boston, Massachusetts; ${ }^{8}$ Pathfinder International, Addis Ababa, Ethiopia; ${ }^{9}$ The Center for Innovation in Global Health, Stanford University, \\ Stanford, California
}

\begin{abstract}
Nomadic pastoralists are among the world's hardest-to-reach and least served populations. Pastoralist communities are difficult to capture in household surveys because of factors including their high degree of mobility over remote terrain, fluid domestic arrangements, and cultural barriers. Most surveys use census-based sampling frames which do not accurately capture the demographic and health parameters of nomadic populations. As a result, pastoralists are "invisible" in population data such as the Demographic and Health Surveys (DHS). By combining remote sensing and geospatial analysis, we developed a sampling strategy designed to capture the current distribution of nomadic populations. We then implemented this sampling frame to survey a population of mobile pastoralists in southwest Ethiopia, focusing on maternal and child health $(\mathrm{MCH})$ indicators. Using standardized instruments from DHS questionnaires, we draw comparisons with regional and national data finding disparities with DHS data in core MCH indicators, including vaccination coverage, skilled birth attendance, and nutritional status. Our field validation demonstrates that this method is a logistically feasible alternative to conventional sampling frames and may be used at the population level. Geospatial sampling methods provide cost-affordable and logistically feasible strategies for sampling mobile populations, a crucial first step toward reaching these groups with health services.
\end{abstract}

\section{INTRODUCTION}

Nomadic pastoralists defy many basic premises of household demographic surveys, including the assumption that individuals are attached to a geographically stable household, and that this household represents a fixed domestic unit. ${ }^{1}$ By contrast, pastoralist settlements are often highly mobile, moving over large areas of remote terrain with the herds of livestock on which they subsist. ${ }^{2}$ Their domestic arrangements are similarly fluid, as family members reside in different geographic locations to manage these livestock. Combined with the dispersed distribution of their encampments and cultural barriers, these mobility patterns make surveying nomadic pastoralists notoriously difficult.

Despite being among the most underserved populations in sub-Saharan Africa, ${ }^{3}$ nomadic pastoralists are also underrepresented in the population data used to plan health interventions. ${ }^{4}$ Large-scale household surveys such as the Demographic and Health Surveys (DHS) Program typically use census-based sampling frames, which magnify and institutionalize the issue of mobile pastoralists' under-enumeration in the original census. Such strategies result in the "statistical invisibility" of nomadic populations. ${ }^{1}$ Lack of accurate data prevents anything but speculative estimates of the global population of mobile pastoralists, but estimates range from 50 to 217.5 million. ${ }^{4,5}$ Pastoralists globally face threats to their health and livelihood, including ecologic disruptions, largescale development projects, conflict, and protracted humanitarian crises. With mounting concerns about emerging

\footnotetext{
*Address correspondence to Hannah Wild, 291 Campus Drive, Stanford University School of Medicine, Stanford, CA 94305-5119, E-mail: hwild@stanford.edu or Luke Glowacki, Department of Anthropology, Pennsylvania State University, University Park, PA. E-mail: glowacki@psu.edu
}

zoonotic pandemic disease, it is critical to find ways of including nomadic populations in household surveys and health surveillance systems.

Numerous methodological approaches to achieving representative samples of mobile populations have been tested, including a "waterpoint approach" in which data are collected at waterholes ${ }^{6}$; a capture-recapture transect approach similar to that used to monitor wildlife ${ }^{7}$; random geographic cluster sampling ${ }^{8}$; and the use of mobile phones. ${ }^{9}$ Many of the approaches explored in these studies have been limited by logistical obstacles or do not lend themselves to being scaled and integrated into data collection exercises such as the DHS.

Geospatial methods present new opportunities for sampling mobile pastoralists and have been used with sedentary populations ${ }^{10,11}$ as well as at the single-village level. ${ }^{12} \mathrm{How}$ ever, geospatial methods have not been used to develop and implement sampling frames at a scale that could be integrated with existing national health surveys. In this study, we develop and assess the utility and feasibility of a geospatial sampling frame to conduct household surveys among a population of mobile pastoralists in a remote region of southwest Ethiopia.

\section{MATERIALS AND METHODS}

Study site and population. The Nyangatom are nomadic pastoralists numbering approximately 25,000 individuals. ${ }^{13}$ They inhabit a remote lowland area of approximately $2,600 \mathrm{~km}^{2}$ on the border between Ethiopia's Lower Omo Valley and South Sudan. Their settlement pattern consists of mobile camps ranging from several families to 200 individuals in size, as well as semi-permanent villages associated with areas of seasonal crop cultivation. The composition of all encampment types is fluid and individuals move between settlements. ${ }^{14}$ There is one market town in Nyangatom in 
which a health clinic is located. Distances to the clinic from Nyangatom settlements vary greatly by region and season but often require significant travel by foot. Our target population included women of reproductive age and their children younger than 5 years. We surveyed 342 mothers of reproductive age and recorded data on the health status of 826 of their children aged 15 years and younger, 547 of whom were younger than 5 years.

Ethical precautions. Verbal informed consent from adults and oral assent from minors was obtained from all study participants. Participants' personal health information (PHI) was protected on researchers' fully encrypted devices with procedures for deidentification of data during analysis, and no $\mathrm{PHI}$ was linked to geospatial data in the public domain. Ethical approval for this study was obtained from the Institutional Review Board for Human Subjects Research at Stanford University School of Medicine, the Ministry of Science and Technology, and the Southern Nations, Nationalities, and Peoples' Regional Health Bureau in Hawassa, Ethiopia.

\section{SAMPLING DESIGN}

We used 0.5-m resolution satellite imagery of the study area in visible and infrared imagery bands, collected within 4 months of survey administration (WorldView-3, April 26, 2017). The imagery was first prepared using the Geographic Data Abstraction Library for pan-sharpening, band-reduction, and export of false-color infrared images in the RGB format, which we used to assist in assessing settlement inhabitance status. The resulting imagery was then converted into an Esri Tile Package and deployed to the ArcGIS Online platform (Redlands, CA) to identify settlements. Using the Hanna Immersive Visualization Environment at Stanford's Institute for Computational and Mathematical Engineering consisting of 35 high definition screens with an effective resolution of $13,440 \times 5,400$, we tagged actively inhabited settlements and recorded WGS84 geospatial coordinates for use in clustering. We defined settlements as the area within $500 \mathrm{~m}$ of an enclosed camp. Encampments have a distinctive visual profile consisting of an outer ring of kraals and a central collection of huts as well as shade structures, storage platforms, and meeting areas (See Figure 1). Among other populations, the composition of settlements will vary, and different features should be used for identification. Because nomadic dwellings are typically constructed from natural materials such as saplings and grass, inhabited versus abandoned settlements can be difficult to distinguish from satellite imagery. Because of the presence of grazing livestock, inhabited settlements contain little interior vegetation, whereas uninhabited settlements tend to be overgrown. We used the presence of significant vegetation in the interior of a settlement as an indicator that the settlement was likely to be uninhabited.

As the only available sampling frame of primary sampling units (PSUs) was based on census data and, therefore, not representative of the target population, we relied on spatial data to divide the entire area into smaller adjacent subregions as homogeneous as possible in terms of population size. We visually identified 225 settlements in the study area, comprising 3,099 huts. With ArcMap's Grouping Analysis tool, we used settlement elevation and K-nearest neighbors for initial grouping analysis, which produced 15 seed points (the maximum number allowed by the program). We then grouped

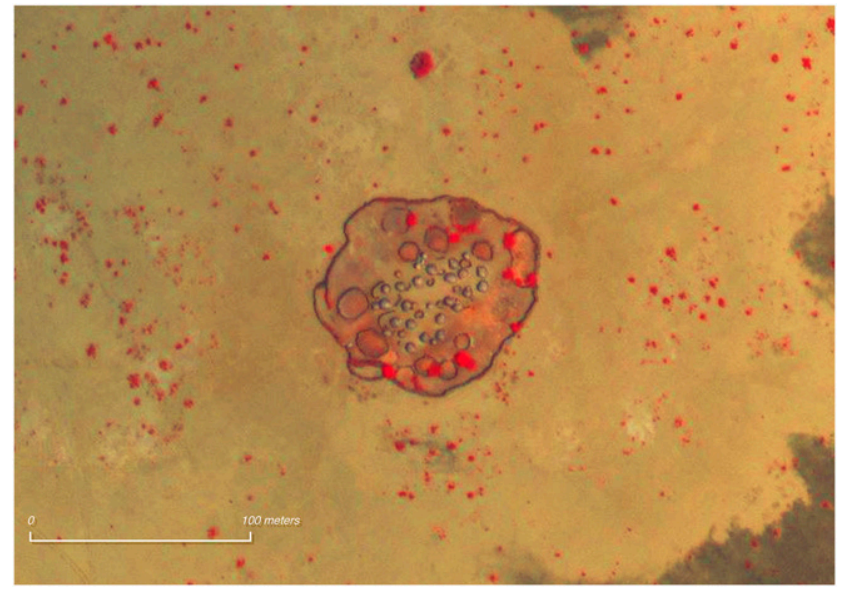

FIGURE 1. Nyangatom settlement (diameter approx. $100 \mathrm{~m}$ ) with huts, livestock kraals, and perimeter fence viewed using infrared and visible multispectral imagery (red indicates vegetation). Captured from imagery covering total land area of $5000 \mathrm{~km}^{2}$ at a resolution of $0.53 \mathrm{~m}$ (imagery provided by DigitalGlobe Foundation, Westminster, CO). This figure appears in color at www.ajtmh.org.

settlements into 15 clusters with an average of 206 huts per cluster around these points based on elevation and spatial proximity. To develop PSUs, we generated Thiessen polygons from these clusters using the spatial median of settlements within each cluster, thereby minimizing the total distance to all points. This process was reiterated until no further change to cluster membership occurred, producing 15 PSUs covering the entire survey area. Although other approaches such as treating individual settlements as the PSU were considered, we favored clustering because the sparse distribution of settlements would have otherwise made conducting the field survey infeasible. Our approach ensured that the survey would be operationalizable, minimizing travel time within clusters and maximizing field team safety. We then selected three PSUs to survey using probability proportional to size sampling based on the number of huts per settlement as identified in the geospatial data. Although a greater number of sampling units could have been selected to provide an even more representative sample, our decision to sample three clusters balanced reducing sampling variability with the financial and logistical constraints of the field survey (see the Sample Size Calculation and Sampling Weights section in Supplementary Information).

Last, we carried out a field survey in the selected PSUs. We used individual settlements as identified in satellite imagery as our secondary sampling unit. We generated a randomized list of all settlements within each cluster, visiting a total of 25 settlements to achieve a sufficient sample size (see the Sample Size Calculation section in Supplementary Information). Within each settlement, we conducted inperson interviews with all women of reproductive age who reported having a birth at any time during the five years preceding the survey. We also collected anthropometric data for the three youngest children aged 0-15 years for each woman in our sample. Our survey instruments were developed using questionnaires from the most recent Ethiopian DHS (EDHS 2016). ${ }^{15}$

Field procedures. For each settlement selected for the field survey, researchers used GPS coordinates obtained 
TABLE 1

Marriage, fertility, and mortality indicators of women and their children (Nyangatom, 2017)

\begin{tabular}{|c|c|c|c|c|}
\hline \multirow[b]{2}{*}{ Indicator } & \multirow{2}{*}{$\frac{\text { Ethiopia DHS } 2016}{\text { Weighted \%/mean (1) }}$} & \multicolumn{2}{|c|}{ Nyangatom 2017} & \multirow[b]{2}{*}{$P$-value* (1) vs. (2 } \\
\hline & & $n$ & Weighted \%/mean (SD) (2) & \\
\hline $\begin{array}{l}\text { Number of all women of childbearing age } \\
\text { interviewed }\end{array}$ & & 347 & & \\
\hline \multicolumn{5}{|l|}{ Marital Status } \\
\hline Unmarried $\dagger$ & & 1 & 0.2 & \\
\hline Married/living together & & 338 & 97.4 & \\
\hline Widowed & & 8 & 2.3 & \\
\hline Total & & 347 & 100.0 & \\
\hline $\begin{array}{l}\text { Mean number of wives per husband (if } \\
\text { married) }\end{array}$ & & 338 & $1.8(1.0)$ & \\
\hline \multicolumn{5}{|l|}{ Wife Order (if other wives) } \\
\hline 1 & & 71 & 39.8 & \\
\hline 2 & & 69 & 38.7 & \\
\hline 3 & & 23 & 12.7 & \\
\hline $4+$ & & 11 & 5.6 & \\
\hline Missing/refused & & 7 & 3.1 & \\
\hline Total & & 181 & 100.0 & \\
\hline Ownership of farm animals $\ddagger$ & 87.6 & 328 & 96.8 & 0.02 \\
\hline \multicolumn{5}{|l|}{ Fertility, children ever born and living§ } \\
\hline $\begin{array}{l}\text { Mean number of pregnancies per } \\
\text { woman of childbearing age }\end{array}$ & & & $5.6(3.4)$ & \\
\hline $\begin{array}{l}\text { Mean number of miscarriages per } \\
\text { woman of childbearing age }\end{array}$ & & & $0.6(0.9)$ & \\
\hline $\begin{array}{l}\text { Mean number of live births per woman } \\
\text { of childbearing age (SD)\| }\end{array}$ & $4.2(2.5)$ & & $5.0(3.1)$ & 0.10 \\
\hline \multicolumn{5}{|l|}{ Mortality } \\
\hline $\begin{array}{l}\text { Mean number of dead children per } \\
\text { woman of childbearing age }\end{array}$ & & & $0.8(1.2)$ & \\
\hline Male child deaths (mean) & & & $0.5(0.8)$ & \\
\hline Female child deaths (mean) & & & $0.3(0.7)$ & \\
\hline $\begin{array}{l}\text { Mean number of living children per } \\
\text { woman of childbearing age (SD) }\end{array}$ & $3.7(2.2)$ & & $4.2(2.4)$ & 0.13 \\
\hline \multicolumn{5}{|c|}{ 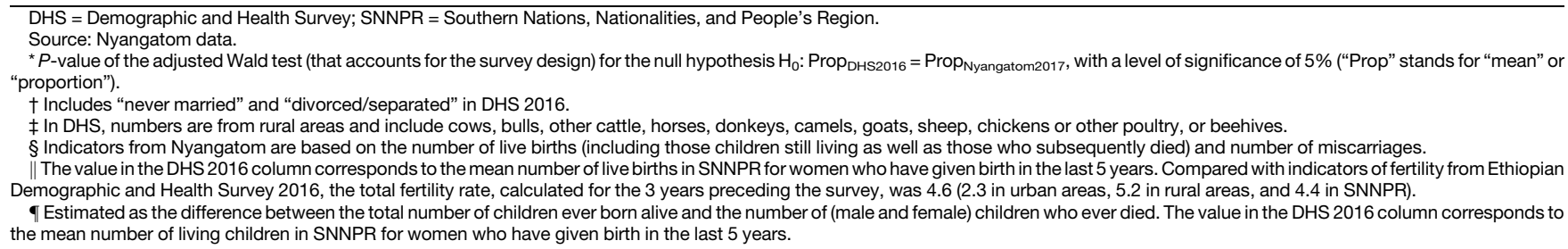 } \\
\hline
\end{tabular}

from satellite imagery to locate nomadic encampments in the field. If on reaching the settlement it was abandoned or could not be located, we selected the spatially nearest replacement. If no spatially proximate alternate could be identified, we selected the next randomly assigned numerical ID in the enumeration list as a replacement. All eligible respondents present within a $500 \mathrm{~m}^{2}$ area surrounding the central point of an enclosed camp tagged from satellite imagery were included. Study personnel adhered to DHS protocols while conducting interviews and obtaining anthropometric measurements. We measured height (cm) and weight $(\mathrm{kg})$ for eligible children younger than 5 years using adjustable ShorrBoard (Olney, MD) measuring boards and digital SECA scales (Hamburg, Germany). Standing height was measured for children aged 2-5 years, and recumbent length was measured for children less than 2 years of age.

Analysis. We conducted descriptive statistical analyses of basic demographic and health indicators for mothers and their three youngest children younger than 16 years. As a benchmark for assessing the health status of our sample in comparison with populations from other regions of Ethiopia, we used the 2016 EDHS survey. ${ }^{15}$ The 2016 EDHS contains information on 16,650 households and 10,335 rural women. Where EDHS data are available at the regional level, we compare our results with data for the Southern Nations, Nationalities, and People's Region (SNNPR), of which the Nyangatom administrative district (woreda) is a part. Where EDHS data are disaggregated only by urban versus rural residence at the national level, we compare our results with data from rural areas.

For mothers in our sample, we report marriage indicators, including marital status, number of co-wives, and wife order, in polygynous marriages. We calculated fertility indicators based on the number of live births and miscarriages per woman, as well as data on subsequent deaths of children. We also collected data on maternal and child health $(\mathrm{MCH})$ indicators, including antenatal care (ANC) visits, services delivered during the ANC visit, location of child birth, vaccination coverage, and autonomy of women to seek health services (full questionnaire in Supplemental Appendix). Consistent with the DHS program, we collected information on treatment-seeking behavior for symptoms of diarrhea, fever, and cough among children younger than 5 years.

We imputed the month of birth for 284 (52\%) children younger than 5 years for whom age was reported in years but not month by using multiple imputation (MI) because age in months was required for the assessment of anthropometric 


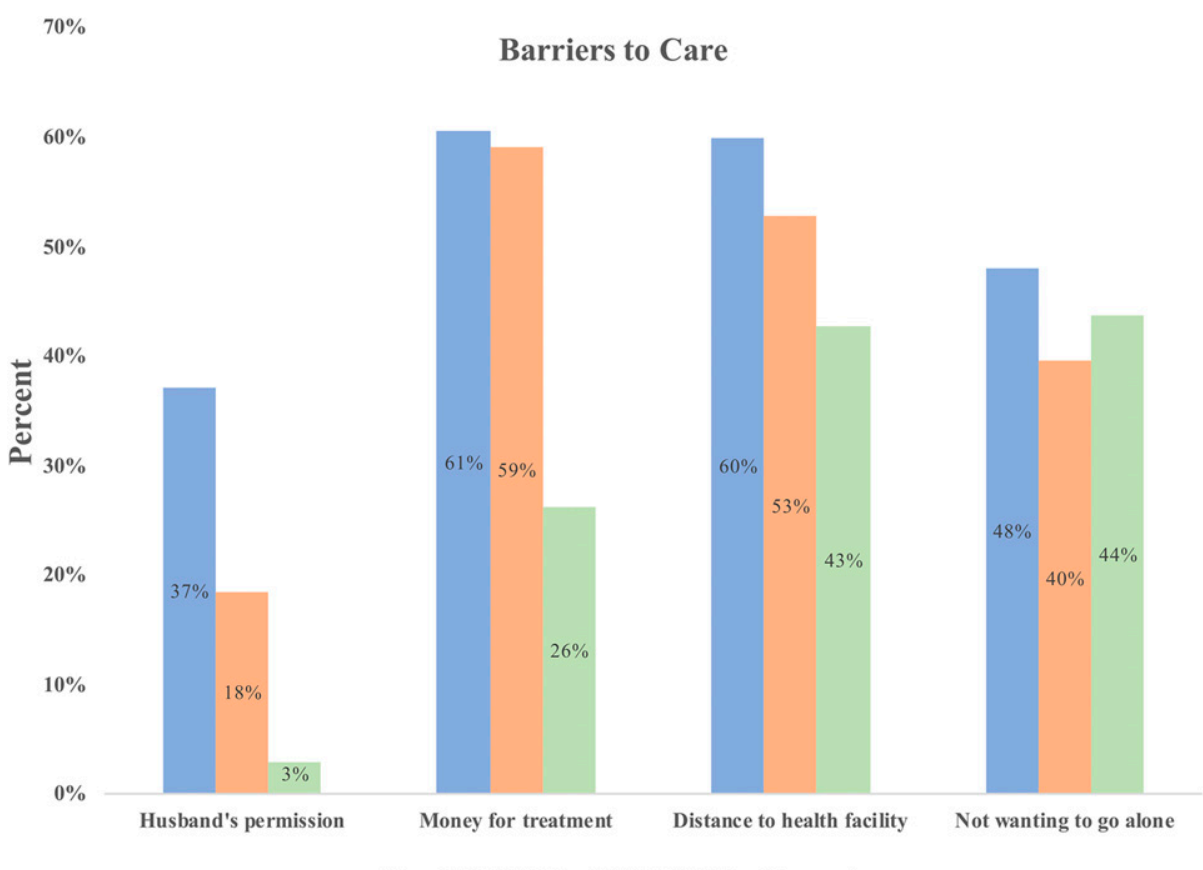

a Rural DHS 2016 = SNNPR 2016 = Nyangatom

FIGURE 2. Women's participation in decision-making about their own health ${ }^{1}$. Source: Nyangatom sample and EDHS (2016). ${ }^{1}$ Excluding the $1 \%$ of respondents who refused. This figure appears in color at www.ajtmh.org.

analysis (see Supplemental Section MI). Raw height and weight measures were converted to age- and gender-specific $z$-scores represented by SD units by using the WHO child growth standards. ${ }^{16}$ We constructed three indicators of anthropometric failure, defined using $z$-scores less than -2 SD of the median height-for-age (HAZ) for stunting, weight-for-age (WAZ) for underweight, and weight-for-height (WHZ) for wasting. Severe anthropometric failure was defined on the basis of $z$-scores less than -3 SD of the respective anthropometric scores. Mid-upper arm circumference (MUAC) was also measured $(\mathrm{cm})$ for children aged 6-59 months and used as an alternative assessment to identify severe acute malnutrition (SAM), defined for infants/children with a MUAC < $11.5 \mathrm{~cm}^{16}$ (see the Methods section in Supplementary Information).

\section{RESULTS}

We interviewed 342 women reporting having given birth during the five years preceding the survey. Maternal age was not recorded because the Nyangatom do not keep track of their own age; however, we assumed a reproductive range of 15-49 years.

Table 1 presents background demographic information on the Nyangatom women of reproductive age included in our analysis, including marriage status, wife ranking, and indicators of fertility and mortality among our sample.

Antenatal care and delivery. Two hundred fifty-six of 342 women (75.9\%) reported receiving ANC at least once during their most recent pregnancy, $71.6 \%$ (95\% Cl: 56.0-83.3\%) of whom visited a skilled provider as defined by the EDHS, including nurses, midwives, health officers, health extension workers, and other medically trained personnel. These rates are comparable with those reported by the 2016 EDHS for women regionally in SNNPR, $69.3 \%$ of whom received ANC services at least once from a skilled provider. Nyangatom women were 4.0 (3.0-6.0) months pregnant (median, IQR) at the time of their first visit to an ANC provider and made an average of 2.8 (2.4-3.2) visits during their most recent pregnancy. The majority of women in our sample who had given birth to a child younger than 5 years at the time of the study did so at their home or another home $(91.2 \%, 95 \% \mathrm{Cl}$ : $61.3-98.6 \%)$, and in a health facility or clinic in only $6.8 \%$ (1.0-36.3\%) of all deliveries. In comparison, the 2016 EDHS found that $72.5 \%$ of women in the region delivered at home, and in a health facility or clinic for $25.5 \%$ of all deliveries. See Supplemental Table 2 for comprehensive descriptive statistics of ANC seeking behavior and antenatal services received.

Problems accessing health care. Women reported that the primary impediments to receiving health care were not wanting to travel alone $(44.0 \%, 95 \% \mathrm{Cl}: 25.6-64.2 \%)$ and distance to the health facility $(43.3 \%, 95 \% \mathrm{Cl}: 17.0-74.0 \%)$.

TABLE 2

Problems accessing health care (Nyangatom, 2017)

\begin{tabular}{lrcc}
\hline & $n$ & Weighted $\%$ & $\mathrm{SE}^{\star}$ \\
\hline Number of respondents (women) & 347 & & \\
Asked permission (yes) & 307 & 91.3 & 2.2 \\
$\begin{array}{l}\text { Permission granted (yes) } \\
\text { Barriers to care identified by respondents }\end{array}$ & 300 & 97.7 & 0.7 \\
$\quad \begin{array}{l}\text { Obtaining permission to go to the } \\
\quad \text { doctor }\end{array}$ & 11 & 2.9 & 1.4 \\
$\quad$ Lack of money required for advice or & 100 & 25.5 & 9.6 \\
$\quad$ treatment & 147 & 43.3 & 7.5 \\
$\quad \begin{array}{l}\text { Distance to health facility } \\
\quad \text { Not wanting to go alone }\end{array}$ & 148 & 44.0 & 4.7 \\
$\quad$ Other† & 41 & 11.8 & 0.5 \\
\hline
\end{tabular}

Source: Nyangatom sample.

† Of the $11.7 \%(41 / 347)$ of women responding that "other" factors prevented them from seeking health care, the majority $(69.7 \%, 28 / 41)$ reported that this problem was due to the requirements of caring for livestock and domestic chores. 
Compared with regional data from the 2016 EDHS in which $76.7 \%$ of women reported being responsible for decisions about her own health care, only $54 \%$ of Nyangatom women in our sample reported being involved in decision-making, whereas $45 \%$ cited their husbands as being the sole party responsible for making decisions regarding the health care for the woman herself (Figure 2). However, only a small proportion $(2.9 \%, 95 \% \mathrm{Cl}: 0.4-20.0,11 / 347)$ of women reported that obtaining permission from her husband to visit a health facility was a barrier to accessing care. Nearly all women requested permission from their husbands before traveling to a health facility $(91.5 \%, 95 \% \mathrm{Cl}: 78.0-97.1 \%)$, but of these women, 97.7\% (95\% Cl: 91.6-99.4\%) reported that their husbands granted them permission all of the time (Table 2).

Women reported having more agency in decision-making for the health care of their children than in their own health care: $61.4 \%$ of women reported being involved in decision-making for the health care of her children. Numerous women reported that they consulted their husbands only to obtain money when they themselves did not possess money for transportation to the clinic or services at the clinic. A lack of alternative arrangements to care for livestock and domestic labor was cited by respondents as a major barrier to care (Table 2).

Children's health. We collected health and anthropometric information from 826 of the children younger than 15 years in our sample (see Supplemental Methods). Our final analytic sample comprised 547 children younger than 5 years, including 262 male children and 285 female children (Table 3 ).

Vaccination status. In our sample, $62.8 \%(95 \% \mathrm{Cl}$ : 23.0-90.5\%, $n=91$ ) of the youngest children between 12 and 35 months of age had ever received at least one vaccination, compared with $84.1 \%$ in SNNPR. Only $14.6 \%(95 \% \mathrm{Cl}$ : $1.8-61.5 \%, 14 / 92)$ of mothers reported ever having a vaccination card in their possession for their children aged 1223 months compared with $42.3 \%$ of children in this age range regionally in the 2016 EDHS, whereas among children aged 24-35 months, 8.8\% (95\% Cl: 0.6-61.0\%, 5/53) of mothers reported ever having been issued a vaccination card versus $34.7 \%$ in the 2016 EDHS. An even smaller percentage (3.9\%, $6 / 145$ ) of respondents were able to present their vaccination card to researchers $(6.4 \%$ for Nyangatom children aged 1223 months compared with $28.8 \%$ of the corresponding age group in the region as reported by the 2016 EDHS). Only $5.9 \%$ (95\% Cl: $0.2-62.5 \%, 5 / 91)$ of mothers reported knowing the purpose of the vaccinations her child had received (Supplemental Table 3).

Treatment for symptoms of Infectious Disease in children. Nyangatom women in our sample sought health treatment for their children younger than 5 years at rates similar to national samples. In cases of diarrheal illness, $49.6 \%$ (95\% Cl, 32.7-66.4) of Nyangatom mothers whose children had diarrhea in the past two weeks sought treatment compared with $47.8 \%$ regionally. Of Nyangatom mothers, $46.6 \%$ whose children had febrile illness in the two weeks preceding the survey date sought treatment for their child's sickness, compared with $36.7 \%$ regionally. Of mothers who sought treatment for their child's illness, the majority visited a health clinic (65.2\% for diarrheal illness and $62.4 \%$ for febrile illness) rather than a traditional provider (32.2\% for diarrheal illness and $32.6 \%$ for febrile illness). See Supplemental Table 4 for complete summary statistics on treatment-seeking.

Anthropometric data. Estimates of HAZ/stunting, WAZ/ underweight, and WHZ/wasting were based on samples comprising 339, 190, and 182 children younger than 5 years, respectively (see Supplemental Methods). Mid-upper arm circumference measurements were recorded for 339 children aged 6-59 months. Nutritional status was favorable among Nyangatom children in comparison with rural data from the 2016 EDHS. This finding was most significant with respect to $\mathrm{WHZ} /$ wasting. In our sample, $13.3 \%$ of children younger than 5 years met criteria for wasting compared with $24.8 \%$ from the 2016 rural EDHS, and only $1.1 \%$ met criteria for severe wasting compared with $7.3 \%$ of children in the 2016 rural EDHS (Figure 3). The lower prevalence of stunting and wasting observed among our sample as compared with the 2016 DHS, calculated using height and weight measurements, was consistent with our finding that very few children $(2.1 \%)$ met the criteria for SAM, calculated using MUAC (see Table 4 for complete results on stunting, wasting, and other anthropometric data).

\section{DISCUSSION}

Our results demonstrate that geospatial sampling frameworks can be used to construct representative samples of

TABLE 3

Sample size and demographic characteristics of 547 Nyangatom children younger than 5 years included in our analysis

\begin{tabular}{lccc}
\hline & & $\begin{array}{c}\text { Month and year of birth } \\
\text { known (OS) weighted \% }\end{array}$ & Weighted \% \\
\hline Number of children in sample & $n$ & & \\
Children younger than 5 years & 826 & & \\
Child gender (younger than 5 years) & 547 & 47.5 & \\
$\quad$ Male & 262 & 52.5 & \\
$\quad$ Female & 285 & 100.0 & $(13.2,19.9)$ \\
$\quad$ Total & 547 & & $(14.3,21.3)$ \\
Sex ratio (male/female $\times 100)$ & 90.4 & 15.6 & $(18.2,26.0)$ \\
Child age* & & 17.5 & $(17.7,25.4)$ \\
0 & 82 & 14.2 & 22.1 \\
1 & 97 & 29.1 & 21.6 \\
2 & 74 & 23.6 & 22.0 \\
3 & 166 & 100.0 & 100.0 \\
\hline
\end{tabular}

$\mathrm{Ml}=$ multiple imputation.

Source: Nyangatom sample.

* Values and percentages in (OS) are based on reported month and year of birth. Percentages and $95 \% \mathrm{Cl}$ in (MI) were calculated using 120 imputed values on month of birth. 


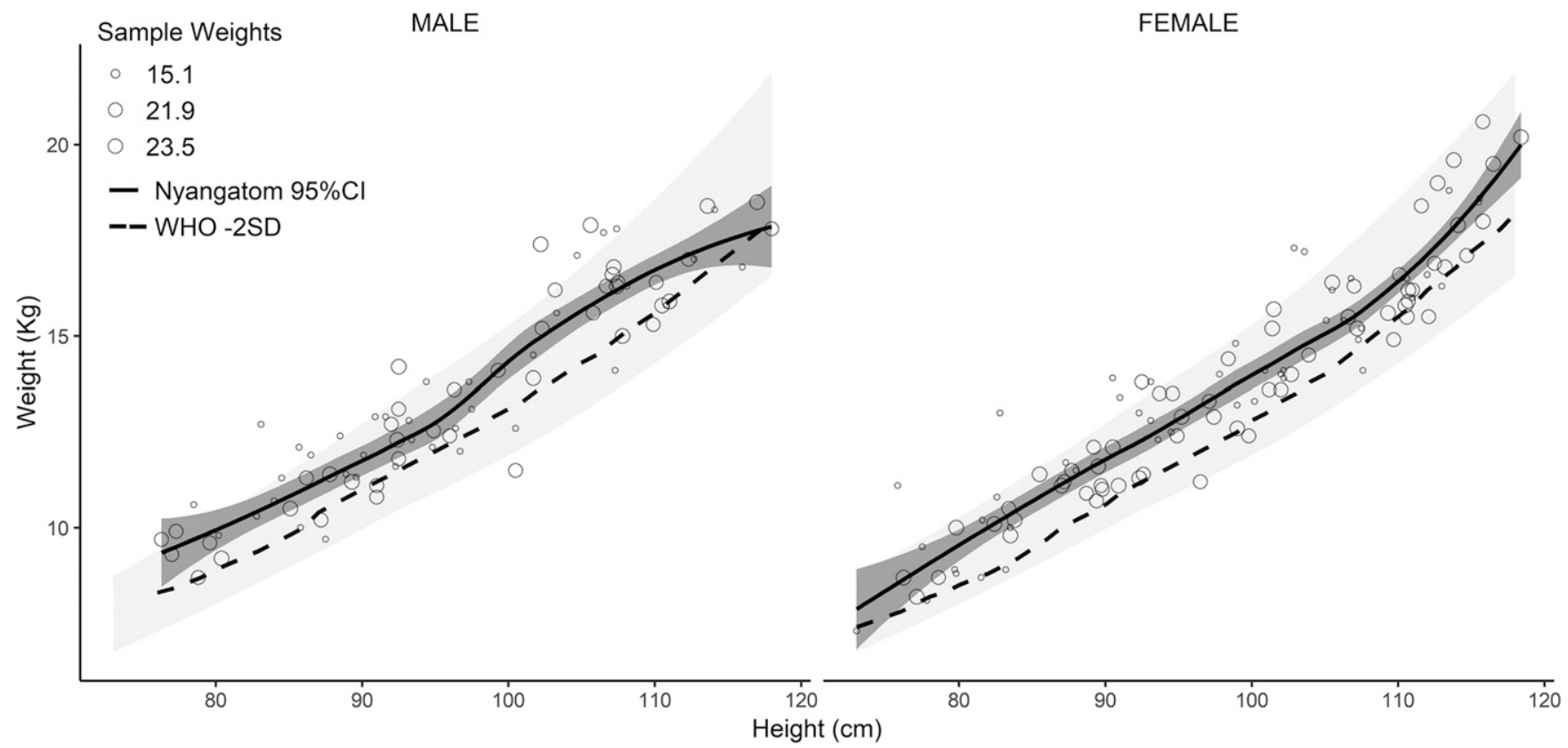

FIGURE 3. Severe acute malnutrition (SAM) and wasting by gender based on weight-for-height of Nyangatom children younger than 5 years in comparison with WHO height-for-weight reference chart values. The lightly shaded region indicates the WHO median to 3 SDs, whereas the darker shaded region is the $95 \% \mathrm{Cl}$ of the Nyangatom sample. Children falling below the dashed line $(<-2 \mathrm{SD})$ meet the WHO definition for wasting, whereas those with <-3 SD meet criteria for SAM. Source: Nyangatom sample and data from WHO-UNICEF $20091^{6}$. Note: Sample restricted to children with valid measures for weight-for-height (using the original sample, $n=73$ ). Observation symbol size represents the probability proportional to size sample weighting $(15.1,21.9$, and 23.5) used in the Loess smoothed regression line and $95 \% \mathrm{Cl}$. Where month of birth was not known, we used multiple imputation to estimate date of birth (month/year; see the Methods section in Supplementary Information).

nomadic populations in a logistically feasible, cost-sensitive manner. Our approach was designed to overcome the limitations of census-based sampling frames such as those used by household surveys, including the DHS, the World Bank's Living Standards Measurement Study, and UNICEF's Multiple Indicator Cluster Surveys. Conventional methods fail to account for population mobility, contributing to the exclusion of nomadic groups in survey data.

Although enumerations using geospatial imagery have been reported at the single settlement level, ${ }^{12}$ this is to our knowledge the first time a geospatial sampling frame was implemented to conduct a population-level assessment. Previous studies found that dispatching survey personnel without first determining the inhabitance status of randomized geographic regions was logistically infeasible. ${ }^{8}$ By enumerating currently inhabited settlements in advance, we were able to assess active population distributions to generate density estimates in a remote, difficult-to-access area. We then demonstrated the logistical feasibility of this method through our field validation.

The use of recent satellite imagery played a crucial role by providing nearly real-time information about the distribution of the target population. Of the 25 settlements selected for survey, two exhibited signs of very recent abandonment (both were active when scouted in the week before the intended date of survey, but abandoned by the time of survey), two showed signs of abandonment at a more distant time point (demonstrating the limitations of identifying settlement status from space), and one site was not located because of a suspected faulty coordinate pair. Refining our methods in the future, we expect that we will be able to compress the timeline from satellite imagery capture to survey deployment, reducing the number of settlements abandoned by the time of the field team's arrival. For subsequent surveys, we recommend visual confirmation and coordinate checks for all selected settlements, once the sampling frame has been generated.

Once the satellite imagery for our study was prepared, manual reconnaissance required $\sim 6$ hours to visually enumerate settlements in an area of over $5,000 \mathrm{~km}^{2}$. This approach is minimally resource intensive over large areas of terrain characteristic of pastoralist environments. Our method depends on environmental features such as sparse vegetation and the distinctive visual signature of settlements. Although implementation may be more difficult in heavily forested settings, nomadic populations tend to inhabit areas of sparse vegetation similar to the conditions of our study area. For this reason, we believe that our methods should be generalizable to nomadic pastoralists in general, and in subSaharan Africa in particular. In addition, we believe that machine automation of parts of the reconnaissance process will be possible, reducing human intervention to verification. ${ }^{17}$ The increasing availability of high-resolution, high-cadence satellite imagery and software pipelines for automated preprocessing and feature extraction will reduce human reconnaissance time and increase the capacity for greater geographic coverage.

Integration with existing DHS methodology is crucial. This could be carried out by working with Ministries of Health and other national partners to identify pastoralist regions in which a geospatial approach should be implemented in favor of traditional census-based enumerations. Survey weighting and population estimates remain a challenge. However, we feel that our approach provides the possibility of more accurate population estimates than existing methods. 
TABLE 4

Nutrition status children younger than 5 years, Nyangatom 2017

\begin{tabular}{|c|c|c|c|c|c|c|c|c|c|}
\hline \multirow[b]{2}{*}{ Anthropometric failure } & \multicolumn{2}{|r|}{$\begin{array}{l}\text { Ethiopia DHS } 2016 \\
\text { (weighted Mean/\%) }\end{array}$} & \multicolumn{3}{|c|}{$\begin{array}{l}\text { Month and year of } \\
\text { birth known }\end{array}$} & \multirow[b]{2}{*}{$\begin{array}{l}\text { (1) vs. (2) } \\
P \text {-value* }\end{array}$} & \multicolumn{3}{|c|}{$\begin{array}{l}\text { Month of birth estimated by } \\
\text { multiple imputation }\end{array}$} \\
\hline & Rural & $\begin{array}{c}\text { Southern Nations, } \\
\text { Nationalities, } \\
\text { and People's Region (1) }\end{array}$ & $n$ & $\begin{array}{l}\text { Weighted } \\
\text { (mean/\%) (2) }\end{array}$ & $95 \% \mathrm{Cl}$ & & $\mathrm{n}$ & $\begin{array}{l}\text { Weighted } \\
(\text { mean/\%) (3) }\end{array}$ & $95 \% \mathrm{Cl}+$ \\
\hline \multicolumn{10}{|l|}{ HAZ/stunting } \\
\hline Sample size $(n)$ & & & 164 & & & & $337 \ddagger$ & & \\
\hline Mean HAZ (95\% Cl) & -1.5 & -1.5 & & -0.88 & $(-1.77,0.01)$ & 0.10 & & -0.83 & $(-1.09,-0.56)$ \\
\hline Stunted $n(\%)$ & 39.9 & 38.6 & 59 & 35.3 & $(23.9,48.8)$ & 0.38 & & 33.7 & $(28.1,39.3)$ \\
\hline Severely stunted & 18.4 & 20.2 & 36 & 21.2 & $(11.5,35.8)$ & 0.76 & & 19.4 & $(14.7,24.1)$ \\
\hline \multicolumn{10}{|l|}{ WAZ/underweight } \\
\hline Sample size $(n)$ & & & 78 & & & & 190 & & \\
\hline Mean WAZ (95\% Cl) & -0.5 & -0.2 & & -0.89 & $(-1.76,-0.03)$ & 0.07 & & -0.77 & $(-0.96,-0.58)$ \\
\hline Underweight $n(\%)$ & 10.1 & 6.0 & 21 & 26.9 & $(17.4,39.3)$ & 0.01 & & 18.5 & $(12.4,24.6)$ \\
\hline Severely underweight & 3.0 & 1.7 & 6 & 7.1 & $(1.0,36.4)$ & 0.22 & & 4.5 & $(1.4,7.6)$ \\
\hline \multicolumn{10}{|l|}{ WHZ/Wasting } \\
\hline Sample size $(n)$ & & & 73 & & & & 182 & & \\
\hline Mean WHZ (95\% Cl) & -1.2 & -1.0 & & -1.08 & $(-1.52,-0.65)$ & 0.50 & & -1.09 & $(-1.21,-0.96)$ \\
\hline Wasting $n(\%)$ & 24.8 & 21.1 & 14 & 18.3 & $(5.2,47.9)$ & 0.63 & & 13.3 & $(8.3,18.4)$ \\
\hline Severe wasting & 7.3 & 6.4 & 2 & 2.7 & $(0.4,16.6)$ & 0.09 & & 1.1 & $(-0.4,2.5)$ \\
\hline \multicolumn{10}{|l|}{ MUAC, $\mathrm{cm}$} \\
\hline $\begin{array}{l}\text { Sample size (Number of } \\
\text { children younger than } 5 \\
\text { years }>6 \mathrm{~m} \text { ) }\end{array}$ & & & 157 & & & & 336 & & \\
\hline Mean $(\mathrm{cm})$ & & & & 13.5 & $(12.8,14.2)$ & & & 13.6‡ & $(13.5,13.7)$ \\
\hline $\begin{array}{l}\text { Severe acute } \\
\text { malnutrition: MUAC < } \\
11.5 \mathrm{~cm})\end{array}$ & & & 4 & 1.1 & $(0.9,1.3)$ & & & 2.2 & $(0.6,3.8)$ \\
\hline
\end{tabular}

Compared with the 2016 EDHS sample regionally and in rural areas nationally, Nyangatom women demonstrate a relatively high uptake of ANC services. Recent NGO- and government-supported initiatives, including the provision of free $\mathrm{MCH}$ services at the nearest health clinic as well as recent road construction increasing access to transportation may explain this trend. Our finding that, under certain conditions, pastoralist women seek treatment at health facilities at rates comparable with regional non-pastoralist populations counters narratives that pastoralists tend to underutilize health services because of cultural beliefs or preferences for traditional healers. ${ }^{18}$ At a minimum, our findings suggest that such reports cannot be extrapolated to characterize the health-seeking behavior of pastoralist populations in general.

Despite higher ANC-seeking rates, skilled birth attendance (SBA) was significantly lower (6.4\%) among the Nyangatom compared not only with the average from rural areas nationally $(21.2 \%)$, but also lower than the lowest regional figure reported by the 2016 Ethiopia DHS (16.4\% in the Afar region). The national trend in the reduction of at-home births has not reached this population, and the vast majority of births occur at home $(91.2 \%)$ compared with the national rural average (79.0). Only $6.8 \%$ of women in our sample delivered at a health facility versus $19.6 \%$ in rural areas nationally. The determinates of this discrepancy would benefit from further research. Antenatal care services may be more accessible for pastoralist women because they can time their visits when their encampments are settled in a location favoring travel to a health facility. By contrast, pastoralist women may be unable to time their deliveries to give birth at a health clinic, as they frequently continue to migrate with mobile livestock encampments and perform domestic labor in locations distant from health facilities throughout their pregnancy. Although the generalizability of this finding to other pastoralist populations should be investigated, this finding highlights opportunities to target programming, outreach, and research toward SBA and delivery practices among pastoralists.

Although limited by lack of reliable documentation, Nyangatom children in our sample had low vaccination coverage compared with the EDHS, with only $62.8 \%$ of Nyangatom children aged 12-35 months having ever received a vaccination versus $84.1 \%$ of children regionally in SNNPR. The majority of our respondents did not retain possession of their vaccination cards even when these documents had been provided to them, or produced documents that were unreadable because of weathering from dirt and mold. As a result, mothers were not able to furnish definitive documentation of full immunization coverage for any of the children in our sample. By mothers' recall, these findings are consistent with other reports of low rates of vaccination coverage among other pastoralist populations. ${ }^{19-21}$

Ethiopia's National Expanded Programme on Immunization has identified pastoralists as the predominant population at risk for missing immunization services. ${ }^{22}$ Many respondents in our sample reported that their children missed vaccination events while residing in a different area than where coverage was provided. These accounts are similar to those of Fulani 
pastoralists in Nigeria, most of who reported they were missed by supplementary immunization activities during an oral polio vaccination campaign because of absence of the child at the time of health workers' visit. ${ }^{23}$ Such studies provide support for the argument that sampling bias may lead to substantial inaccuracies in estimates of vaccination coverage, ${ }^{24}$ and suggest that even mobile vaccination programs may be insufficient if they are not informed by knowledge of seasonal transhumance patterns.

Our findings suggest that conventional narratives of factors preventing pastoralist women from seeking health care may be inaccurate in some settings. Among our study population, participants reported that money, women's empowerment, and distance to a health facility were not as significant an impediment to seeking care as insecurity and the issue of domestic labor. Subsistence livelihoods rely on daily labor from female household members such as milking and watering livestock, and collecting firewood and water. Whereas for urban populations lack of access to money may be a major impediment, among pastoralists, the requirements of household labor may be more significant. Likewise, living in a patriarchal society such as that of the Nyangatom cannot be interpreted to mean that obtaining permission from husbands is a significant barrier to care. This finding differs from previous studies reporting that men's control over health-care decisions is a primary barrier to care for pastoralist women. ${ }^{21,25}$ Although most women in our sample needed to obtain their husband's permission to seek care, the vast majority (97\%) reported they were granted this permission all of the time and that this was not, therefore, a barrier to care.

Nyangatom children in our sample had a lower prevalence of SAM and stunting compared with national averages. Although we believe that these results represent adequate nutritional status of the pastoralist children in our sample, the issue of survivorship remains a possibility if undernourished children do not survive to appear in our sample. For children older than approximately 6 months, our results are consistent with findings from previous research demonstrating that settled children may have poorer nutritional status. This has been attributed to decreased access to milk and animal products associated with a sedentarized diet, even when total caloric intake may be greater. ${ }^{26,27}$ There may be variability between populations, as other studies have found children of nomadic families to have unfavorable nutritional status compared with sedentary counterparts. ${ }^{20,28}$ These findings underscore that arguments for sedentarization premised on improvements in childhood nutritional status (historically put forward by development agencies, national governments, and nongovernmental organizations) must have an empiric basis. ${ }^{27}$ An unexpected finding of our study concerned the misuse of veterinary medicine for self-treatment. Numerous mothers reported administering livestock medicine to their children, including the use of injectable cattle ivermectin applied directly to the eyes for pediatric ophthalmic illness, and veterinary oxytetracycline as an orally administered antitussive. This potentially concerning practice merits further research.

The limitations of this study highlight several challenges inherent in surveying pastoralist populations. First, most Nyangatom women in our study population were unable to accurately date events and ages. As a result, it was necessary to impute ages for a number of children in our sample, with a potential impact on indicators depending on children's precise age. Second, the domestic labor schedules of our participants constrained both the hours during which it was feasible to collect data as well as participants' susceptibility to survey fatigue, limiting the length of our survey. During data collection, women were occupied chasing birds away from their fields and often left their dwellings before dawn. For similar reasons, we were unable to interview household heads, who herded cattle during the day and were rarely present in the same location as women participants.

Our findings suggest several ways in which $\mathrm{MCH}$ interventions among pastoralists can be improved. First, vaccination outreach campaigns should coordinate their timing to occur when settlements are at their largest size (among the Nyangatom, this is during the wet season), to avoid missing inhabitants of livestock encampments dispersed across remote grazing territory in times of scarcity. ${ }^{26}$ Second, alternative record-keeping systems for immunizations should be developed and implemented with pastoralists. Nomadic households are unlikely to retain these documents, and paper cards will not weather exposure to the elements incurred during frequent migrations.

In addition, our findings suggest that men's control over health-care decisions may not be a major barrier to pastoralist women's ability to seek care even in cases where a husband's permission is required. By contrast, domestic labor and responsibilities such as caring for the family's livestock, homestead, and other children appear to be significant and underrecognized barriers to pastoralist women seeking care. Efforts targeting these domains may be more effective in improving $\mathrm{MCH}$ among pastoralists, and empirically informed studies investigating the determinants of health-seeking behavior should be used to guide programming and decision-making. Interventions focusing on men's awareness, for example, may not be as effective or impactful as providing secure, expedient transportation to a clinic to minimize time away from the household.

Despite pastoralist groups' long history of invisibility in population data, our sampling design and successful field deployment indicate that geospatially derived sampling frames hold potential for the systematic inclusion of mobile populations in household surveys. This method is a viable alternative for use in pastoralist regions and has the potential to increase the representation of mobile populations in survey data. The disparities we found between the study population and DHSderived country estimates for certain $\mathrm{MCH}$ indicators suggest that without the implementation of sampling strategies capable of accounting for mobility, key indicators in data used to monitor progress on Sustainable Development Goals and other targets may present an inaccurate picture of pastoralists' health status.

Above all, we propose that policymakers and national governments implement the use of geospatial sampling frames in pastoralist regions to reduce under-coverage and prevent bias in national estimates. This is a crucial step toward designing health systems and implementing longitudinal health surveillance for underserved mobile groups. Such an approach can aid in more effectively targeting the limited resources of national Ministries of Health and serve as an overdue foundation to include mobile pastoralists in frameworks to achieve universal health coverage.

Received December 27, 2018. Accepted for publication June 18, 2019.

Published online August 19, 2019. 
Note: Supplemental files and appendix appear at www.ajtmh.org.

Acknowledgments: We thank the College of Development Studies at Addis Ababa University for hosting our research, including Dilu Shaleka and Emezat Mengesha; Elias Alemu and Hannah Getachew of Hawassa University School of Behavioral Sciences; Gemechu Kuffa and colleagues at the SNNPR Health Bureau; and the Nyangatom Administration, especially Lore Kakuta. We are particularly grateful for the logistical support provided by Semie Anbesse, as well as by Zelalem Worku. We thank Solomon Tilahun for providing shapefiles used in geospatial analysis and Mina Mousa of Stanford University School of Medicine's Information Resources and Technology for remote technical support, which was essential for our fieldwork.

Financial support: This work was supported by Stanford MedScholars Program, the Stanford Center for African Studies, and the American Society of Tropical Medicine and Hygiene Benjamin H. Kean Fellowship. The DigitalGlobe Foundation generously provided the satellite imagery used to conduct this study.

Authors' addresses: Hannah Wild, Stanford University School of Medicine, Stanford, CA, E-mail: hwild@stanford.edu. Luke Glowacki, Department of Anthropology, Pennsylvania State University, E-mail: glowacki@psu.edu. Stace Maples, Stanford Geospatial Center, Stanford University, Stanford, CA, E-mail: stacemaples@stanford. edu.Iván Mejía-Guevara, Department of Biology, Stanford University, and Stanford Center for Population Health Sciences, Stanford University School of Medicine, Stanford, CA, E-mail: imejia@stanford. edu. Amy Krystosik and A. Desiree LaBeaud, Division of Infectious Disease, Department of Pediatrics, Stanford University School of Medicine, Stanford, CA, E-mail: akrystos@stanford.edu and dlabeaud @stanford.edu. Matthew H. Bonds, Department of Global Health and Social Medicine, Harvard Medical School, Boston, MA, E-mail: matthew_bonds@hms.harvard.edu. Abiy Hiruy, Pathfinder International, Addis Ababa, Ethiopia, E-mail: ahiruy@pathfinder.org. Michele Barry, The Center for Innovation in Global Health, Stanford University, Stanford, CA, E-mail: michele.barry@stanford.edu.

This is an open-access article distributed under the terms of the Creative Commons Attribution License, which permits unrestricted use, distribution, and reproduction in any medium, provided the original author and source are credited.

\section{REFERENCES}

1. Randall S, 2015. Where have all the nomads gone? Fifty years of statistical and demographic invisibilities of African mobile pastoralists. Pastoralism 5: 22.

2. Zinsstag J, Taleb MO, Craig PS, 2018. Health of nomadic pastoralists: new approaches towards equity effectiveness. Trop Med Int Health 11: 565-568.

3. Montavon A et al., 2018. Health of mobile pastoralists in the Sahel-assessment of 15 years of research and development. Trop Med Int Health 18: 1044-1052.

4. Carr-Hill RA, 2013. Measuring progress toward the millennium development goals and the missing millions. World Health Popul 14: 4-11.

5. El Shiekh B, van der Kwaak A, 2015. Factors influencing the utilization of maternal health care services by nomads in Sudan. Pastoralism 5: 23.

6. Kalsbeek WD, 1986. Nomad sampling: an analytic study of alternative design strategies. Proc. Sect. Surv. Res. Methods pp. 164-169. Available at: http://www.asasrms.org/Proceedings/ papers/1986_028.pdf.

7. Weibel D, Schelling E, Bonfoh B, Utzinger J, Hattendorf J, Abdoulaye M, Madjiade T, Zinsstag J, 2008. Demographic and health surveillance of mobile pastoralists in Chad: integration of biometric fingerprint identification into a geographical information system. Geospat Health 3: 113-124.

8. Himelein K, Eckman S, Murray S, 2014. Sampling nomads: a new technique for remote, hard-to-reach, and mobile populations. J Off Stat 30: 191-213.

9. Jean-Richard V, Crump L, Daugla DM, Hattendord J, Schelling E, Zinsstag J, 2014. The use of mobile phones for demographic surveillance of mobile pastoralists and their animals in Chad: proof of principle. Glob Health Action 7: 23029.
10. Chen X, Hu H, Xu X, Gong J, Li F, 2018. Probability sampling by connecting space with households using GIS/GPS technologies. J Surv Stat Methodol 6: 149-168.

11. Haenssgen MJ, 2015. Satellite-aided survey sampling and implementation in low- and middle-income contexts: a lowcost/low-tech alternative. Emerg Themes Epidemiol 12: 20.

12. Pearson AL, Rzotkiewicz A, Zwickle A, 2015. Using remote, spatial techniques to select a random household sample in a dispersed, semi-nomadic pastoral community: utility for a longitudinal health and demographic surveillance system. Int $J$ Health Geogr 14: 33.

13. UNFPA (United Nations Population Fund), 2008. Summary and Statistical Report of the 2007 Population and Housing Census: Population Size by Age and Sex. Available at: http://agris.fao.org/ agris-search/search.do?recordID=XF2015048396. Accessed June 30, 2018.

14. Glowacki L, Wrangham R, 2015. Warfare and reproductive success in a tribal population. Proc Natl Acad Sci 112: 348-353.

15. Central Statistical Agency, 2016. Ethiopia Demographic and Health Survey 2016. Available at: http://dhsprogram.com/publications/ publication-FR328-DHS-Final-Reports.cfm. Accessed June 30, 2018.

16. World Health Organization, 2009. WHO Child Growth Standards and the Identification of Severe Acute Malnutrition in Infants and Children: Joint Statement by the World Health Organization and the United Nations Children's Fund Available at: https://apps.who.int/ iris/bitstream/handle/10665/44129/9789241598163_eng.pdf; jsessionid=DAB016C3481B3E365DD9DC7DB408BC88? sequence $=1$.

17. Walker, RS, Hamilton, MJ, 2019. Machine learning with remote sensing data to locate uncontacted indigenous villages in Amazonia. PeerJ Comput Sci 5: e170.

18. Haasnoot PJ, Boeting TE, Kuney MO, van Roosmalen J, 2010. Knowledge, attitudes, and practice of tuberculosis among Maasai in Simanjiro district, Tanzania. Am J Trop Med Hyg 83: 902-905.

19. Sheik-Mohamed A, Velema JP, 2018. Where health care has no access: the nomadic populations of sub-Saharan Africa. Trop Med Int Health 4: 695-707.

20. Lawson DW, Mulder M, Ghiselli M, Ngadaya E, Ngowi B, Mfinanga S, Hartwig K, James S, 2014. Ethnicity and child health in northern Tanzania: Maasai pastoralists are disadvantaged compared to neighbouring ethnic groups. PLoS One 9: e110447.

21. Schelling E, Weibel D, Bonfoh B, 2008. Learning from the Delivery of Social Services to Pastoralists: Elements of Good Practice. Nairobi, Kenya: WISP/IUCN.

22. Ethiopian Federal Ministry of Health, World Health Organization, United Nations Children's Fund, 2015. Ethiopia National Expanded Programme on Immunization. Available at: http://www. nationalplanningcycles.org/sites/default/files/country_docs/ Ethiopia/ethiop_cmyp_latest_revised_may_12_2015.pdf. Accessed October 10, 2018.

23. Michael CA et al.; OPV Campaign Missed Children Study Team, 2014. An evaluation of community perspectives and contributing factors to missed children during an oral polio vaccination campaign-Katsina state, Nigeria. J Infect Dis 210: S131-S135.

24. Cutts FT, Izurieta HS, Rhoda DA, 2013. Measuring coverage in $\mathrm{MNCH}$ : design, implementation, and interpretation challenges associated with tracking vaccination coverage using household surveys. PLoS Med 10: e1001404.

25. Hampshire K, 2002. Networks of nomads: negotiating access to health resources among pastoralist women in Chad. Soc Sci Med 54: 1025-1037.

26. Leslie PW, Little MA, 1999. Turkana Herders of the Dry Savanna: Ecology and Biobehavioural Response of Nomads to an Uncertain Environment. Oxford, UK: Oxford University Press.

27. Fratkin E, Roth EA, Nathan MA, 2004. Pastoral sedentarization and its effects on children's diet, health, and growth among rendille of northern Kenya. Hum Ecol 32: 531-559.

28. Galvin KA, Beeton TA, Boone RB, BurnSilver SB, 2015. Nutritional status of Maasai pastoralists under change. Hum Ecol 43: 411-424 